\title{
EU NÃO ME DAVA MUITO BEM COM A ESCOLA: UM ESTUDO COM JOVENS DO ENSINO MÉDIO
}

\author{
http://dx.doi.org/10.5902/2176217113539
}

\author{
Ethiana Sarachin da Silva Ramos \\ Universidade Federal de Santa Maria, Brasil. \\ Sueli Salva \\ Universidade Federal de Santa Maria, Brasil.
}

\begin{abstract}
Resumo
Neste artigo apresentam-se os resultados da pesquisa intitulada Culturas juvenis e formação educacional: um estudo com jovens estudantes de Santa Maria que se afastam dos processos formativos, pela qual se buscou compreender os motivos que levam muitos jovens a se afastarem dos processos formativos escolares. A metodologia utilizada baseou-se no paradigma qualitativo de cunho etnográfico. Foram utilizados instrumentos de produção de dados como observação, entrevista aberta e diário de campo. Os resultados evidenciaram que os processos de afastamento têm início ainda no ensino fundamental e que a fragilidade do vínculo entre a escola e o aluno está ligada a um processo de resistência, relacionada a fatores como metodologias inadequadas e problemas no processo de comunicação.

Palavras-chave: políticas públicas, juventude, escola, ensino médio.
\end{abstract}

\section{DO NOT GAVE VERY WELL WITH SCHOOL: A STUDY WITH YOUNG MIDDLE SCHOOL}

\section{Abstract}

This article presents the results of research entitled Youth cultures and education: a study with young students of Santa Maria that departed from the formative processes, which sought to understand the reasons that lead many young people to move away from school training processes. The methodology used was based on ethnographic qualitative paradigm. Instruments of production data such as observation, interview and open field diary were used. The results showed that the process of alienation still start at the elementary school and the weakness of the link between the school and the student is linked to a process of resistance, related to factors such as inadequate methodologies and problems in the communication process.

Key-words: public policies, youth school, high school. 


\section{Introdução}

ste trabalho teve origem no projeto de pesquisa intitulado Culturas juvenis e formação educacional: um estudo com jovens estudantes de Santa Maria que se afastam dos processos formativos. O referido projeto teve como objetivo compreender os motivos pelos quais muitos jovens a se afastam da instituição escolar. Assim, busca-se refletir sobre os modos de vida dos jovens, com vistas a conhecer os processos culturais, sociais e institucionais que os envolvem e entender a relação dos jovens com os professores e colegas.

Os dados produzidos nessa pesquisa são relevantes na medida em que podem contribuir para políticas públicas mais condizentes com as realidades dos jovens das escolas públicas, considerando que cada contexto é diferente de outro e que, portanto, não podemos fazer generalizações, mas tentar compreender o jovem a partir dele mesmo.

A pesquisa está embasada, principalmente, em Moehleke (2012), Spósito (2005), Tomazetti et al (2012), Dayrell (2003) e Freire (1996).

\section{O ensino médio no Brasil e a juventude}

O ensino médio no Brasil tem passado por várias transformações. No início, o ensino médio era destinado à elite e visava à preparação para a continuação dos estudos, isto é, ao ingresso no ensino superior (Moehleke, 2012). Na década de 1930 houve reformas educacionais, especificamente no caráter introdutório do ensino médio. As indústrias começaram a surgir e necessitava-se de mão de obra. Com isso, foi implantado o ensino médio profissionalizante, reservado às classes menos favorecidas economicamente.

A Constituição Federal de 1988 trouxe alterações importantes como, por exemplo, o dever do Estado em assegurar a "progressiva extensão da obrigatoriedade e gratuidade do ensino médio" (artigo 208, inciso II). Dessa forma, a escola tornou-se mais permeável ao contexto social e suas influências, recebendo uma quantidade cada vez mais heterogênea de alunos, marcados pelo contexto de uma sociedade desigual com altos índices de pobreza e violência. A escola, segundo Sposito (2005), passou a conviver com os conflitos e contradições de uma estrutura social e excludente. Com a significativa migração dos alunos das camadas altas e médias para a rede particular de ensino, a escola pública consolidou-se como uma escola para pobres. Nesse processo, o próprio sentido do ensino médio se transformou: antes, o caminho natural para continuação dos estudos; agora, uma etapa obrigatória o final do percurso da escolarização. Apesar de várias iniciativas do poder público, não houve ainda uma adequação da estrutura escolar a esta nova realidade.

Com a Lei de Diretrizes e Bases da Educação de 1996 o ensino médio, no Brasil, tornou-se a etapa final da educação básica. Antes dessa lei poucos eram os jovens que chegavam ao ensino médio. Segundo Moehlecke (2012, p. 41), "a intenção de imprimir ao ensino médio uma identidade associada à formação básica que deve ser garantida a toda a população, no sentido de romper a dicotomia entre ensino profissionalizante ou preparatório para o ensino superior."

Apesar do avanço no âmbito legal, as escolas brasileiras parecem desconhecer as culturas juvenis, desconsiderando o sentido de mundo que os jovens trazem para 0 
espaço escolar. O ensino médio tornou-se uma etapa de memorização do ensino, desconectado dos anseios e objetivos dos jovens. Muitas vezes a escola percebe essa etapa como preparação para o vestibular ou para concursos públicos (Tomazetti et al, 2012).

Os números atuais, fornecidos pelo Inep, IBGE, Unesco, indicam dados preocupantes no que diz respeito à juventude e à escolarização. O documento Proposta Pedagógica para o ensino médio do governo do Rio Grande do Sul apresenta uma análise diagnóstica do ensino médio da rede estadual de ensino. Segundo o documento, há uma grande preocupação em relação a altos índices de defasagem idade-série, abandono escolar e matrículas nos últimos cinco anos. Esse contexto de transformação do ensino médio é um dos grandes desafios atuais na formulação de políticas públicas educacionais.

Segundo o documento,

a escolaridade líquida (idade esperada para o ensino médio 15-17 anos) é de apenas 53,1\%. A defasagem idade-série no Ensino Médio é de 30,5\%. Da faixa etária de 15 a 17 anos, 108.995 jovens ainda frequentam o Ensino Fundamental (Inep/MEC- Educacenso - Censo Escolar da Educação Básica 2010). Ao mesmo tempo, constatam-se altos índices de abandono (13\%) especialmente no primeiro ano, e de reprovação $(21,7 \%)$ no decorrer do curso, o que reforça a necessidade de priorizar o trabalho pedagógico no ensino médio.

Pesquisas na área da sociologia da juventude também indicam uma realidade preocupante no que diz respeito à escolarização de jovens (Tomazetti, et. al. 2012).

Esse contexto de transformação do ensino médio é apontado por Moehlecke (2012) como um dos grandes desafios atuais na formulação de políticas públicas educacionais. Nesse sentido, pesquisas no âmbito da educação possuem um papel importante na construção de conhecimentos que contribuam para que as políticas públicas educacionais sejam cada vez mais adequadas a esse contexto.

No que se refere ao conceito de juventude consideramos a definição de Dayrell (2003). Para esse autor, "a juventude é, ao mesmo tempo, uma condição social e um tipo de representação" (p. 41). Ela não é apenas uma "etapa com um fim predeterminado, muito menos como um momento de preparação que será superado com o chegar da vida adulta" (p. 42), ela é parte de um processo mais amplo de constituição da identidade de sujeitos, com especificidades marcantes na vida de cada um. A juventude não é somente um momento de passagem, ela tem uma importância em si, constituindo um período determinado.

\section{Metodologia}

A investigação sobre a qual embasamos este artigo se situa dentro da abordagem qualitativa de pesquisa de inspiração etnográfica. Para 0 paradigma qualitativo as pesquisas assumem que o conhecimento é relativo, que há sempre um elemento subjetivo e que apresentam resultados não generalizáveis.

Nesse tipo de pesquisa o objeto é construído à medida que vai se conhecendo, com mais profundidade, o fenômeno estudado, isto é, permite que se reflita sobre os dados no decorrer da produção e da análise dos mesmos. Assim, as hipóteses não são elaboradas 
previamente, mas sim num processo interativo em que estas vão se originando à medida que se aprofunda a análise. Esse processo metodológico é contínuo, o que pode causar a necessidade de se buscar mais dados ou novas teorias que ajudem as análises e interpretações. Lüdke denomina esse movimento de "processo indutivo" (Lüdke, 1986, p. 13). Para essa autora, a abordagem qualitativa se caracteriza por enfatizar mais o processo do que o produto, por investigar a "perspectiva dos participantes" sobre o tema proposto (Lüdke, 1986, p. 12) e, por isso, geralmente, envolve o uso de amostras menores ou estudos de caso. Dessa forma, essa abordagem possibilita que 0 pesquisador tenha um contato direto com o grupo investigado.

Entretanto, é preciso situar a pesquisa em perspectiva mais específica: a da pesquisa etnográfica. Silverman (2009) destaca a definição proposta por Brewer (2000), que afirma que essa perspectiva de investigação caracteriza-se por

investigar pessoas em locais ou 'campo' que ocorrem naturalmente, através de métodos de coleta de dados que captam seus significados sociais e suas atividades comuns, envolvendo a participação direta do pesquisador no local, se não também nas atividades, para coletar dados de uma maneira sistemática. (Silverman, 2009, p. 71)

A etimologia da palavra etnografia possibilita explicar o fundamento da pesquisa etnográfica: etno significa pessoas e grafia significa escrever. Portanto, a etnografia refere-se aos escritos sobre determinadas pessoas. Essa prática exige, por sua vez, 0 uso de certos tipos de recursos ou formas de se coletar e analisar os dados. Nesse sentido, a observação participante e o trabalho de campo são fundamentais. Dessa forma, a referida pesquisa se caracteriza por pertencer à abordagem qualitativa, dentro de uma perspectiva de inspiração etnográfica que utilizou diferentes instrumentos de produção de dados, tais como observação, entrevistas abertas e registros em diário de campo. Para este artigo tomamos como base de análises somente excertos das entrevistas abertas de três estudantes de uma escola pública participante dessa investigação.

A entrevista aberta, de acordo com Orti (1989) consiste em um diálogo face-a-face, direto e espontâneo, em que pesquisados e pesquisadores se sentem livres e desarmados, facilitando a expressão das vivências e da experiência de modo aberto e fluido, ancorada em princípios da pesquisa qualitativa,

que se orientam (de modo intencionalmente específico) para captar (de forma concreta e compreensiva), analisar e interpretar os aspectos significativos diferenciais da conduta e das representações dos sujeitos investigados [ ... ] por isso exige precisamente a livre manifestação pelos sujeitos entrevistados de seus interesses informativos (lembrança espontânea), crenças (expectativas e orientações de valor sobre as informações recebidas) e desejos (motivações internas conscientes e inconscientes) (Ortí, 1989, p. 195)

A entrevista aberta, entre outros instrumentos, faz parte da etnografia, que, segundo André (2000), prevê a produção de uma grande quantidade de dados descritivos, utilizando, principalmente, a observação participante, de maneira que o pesquisador possa acumular descrições das relações, fatos, ações e modos de vida, tendo, assim, a possibilidade de estruturar o quadro figurativo da realidade estudada e, a partir desse 
desenho, realizar as análises e interpretações do fenômeno tentando perceber os percursos realizados pelos jovens estudantes.

O aluno Ozias, 18 anos, cursa o segundo ano do ensino médio, no turno da manhã, etrabalha em um supermercado pela parte da tarde. Esse aluno estudava na escola que faz parte da pesquisa, porém, por causa de uma amiga que também estudava na escola e foi estudar em outra, ele pediu transferência. No entanto, ele não se adaptou às regras estipuladas pela escola e retornou para a escola pesquisada. Paula, 21 anos, cursa 0 terceiro ano do ensino médio/EJA, no turno da noite, trabalha em uma empresa prestadora de serviços gerais. No primeiro ano do ensino médio regular, ela faltava muito e reprovou por cinco anos, até que engravidou e parou de estudar. Em 2012 voltou a estudar e foi para a modalidade EJA. A jovem relatou que voltou a estudar porque quer fazer um curso e almeja uma vida melhor. Também disse fazer a EJA por ser uma forma mais rápida de terminar os estudos. Tatiana, 19 anos, cursa o primeiro ano do ensino médio/EJA, no turno da noite, trabalha como babá pela manhã. A jovem relatou que está cursando a EJA porque se encontra em defasagem idade-série. Ela repetiu o ano por duas vezes e disse que foi convidada pelos professores para passar a estudar no noturno.

\section{As vozes dos jovens}

Ao analisar as entrevistas dos jovens podemos perceber que a infrequência é um fenômeno que inicia ainda no ensino fundamental. Um fato curioso é que um dos alunos entrevistados percebe que, mesmo faltando às aulas, ele pode passar de ano. Ele não faz referência a conteúdo, apenas relata o que ocorre na escola: "Aí na oitava série eu quase não vinha na aula e passei direto, daí no primeiro também quase nunca fazia nada, daí peguei recuperação em três e passei. Nesse ano vai ser igual, eu não tô fazendo nada e acabo passando (Ozias).

É difícil compreender o que quer nos dizer esse aluno, mas poderíamos nos interrogar: a escola desistiu de ser escola para esse aluno? E esse aluno, desistiu de fazer o papel de aluno? Se a escola desistiu desse aluno, o que isso significa? Talvez signifique entregar o aluno a própria sorte, não se preocupar com ele, não se comprometer com ele. Esse jovem parece revelar a fragilidade do vínculo que a escola estabelece com os estudantes. Esse relato também pode estar relacionado com o processo de resistência dos alunos frente uma escola cujos mecanismos priorizam a burocracia, a segmentação de conteúdos. O caso desse aluno parece coincidir com os alunos pesquisados por Abrantes (2003) em algumas escolas da grande Lisboa. Segundo o autor, os alunos constroem uma adesão distanciada com a escola:

Enfadados com o trabalho escolar, sem vislumbrarem grandes alternativas no seu exterior, vão mantendo uma relação flexível e ambígua com a instituição escolar, que lhes permite em certas situações resistir e infringir as regras, noutras participar com entusiasmo. (Abrantes, 2003, p.123)

Resistência que se revela na fala a seguir, quando o aluno é interrogado em relação a não realização, por parte dele, das atividades propostas pelo professor em sala de aula: É preguiça mesmo de ficar copiando, daí eu fico parado olhando pro quadro, conversando (Ozias).

A forma como a dinâmica escolar funciona se contrapõe à vida dinâmica impulsionada pelas mudanças estruturais da sociedade contemporânea. José Machado 
Pais (2006) recorre aos conceitos de espaço estriado e espaço liso, usados por Deleuze e Guattari (1997, p. 184), para explicar a dinâmica escolar. O espaço estriado seria um "sistema fechado, que entrecruza fixos e variáveis, ordena e faz sucederem-se em formas distintas, organiza as linhas melódicas horizontais e os planos harmônicos verticais" e o espaço liso "é a variação contínua, é o desenvolvimento contínuo da forma, é a fusão da harmonia e da melodia em favor de um desprendimento de valores propriamente rítmicos". Os jovens estudantes entendem a escola como um sistema estriado, como um espaço fechado. Os atos de indisciplina e transgressão são uma forma de reclamar "inclusão, pertencimento, reconhecimento [...] vida cotidiana - como um sistema liso, espaços mais libertos dos constrangimentos institucionais do lazer e do lúdico" (Pais, 2006, p. 14).

O processo de distanciamento não é o único problema. Percebe-se que a metodologia empregada pelo professor também pode causar esse tipo de resistência por parte do aluno, como revela o trecho a seguir, quando a aluna foi perguntada sobre o que pensa sobre a metodologia utilizada pelos professores:

Depende de cada professor, tem professor que nos leva na sala de informática, nos trás livros, não é só esse livro (nesse momento ela aponta para o livro didático) às vezes o livro enjoa e há outros professores que traz livros novos da faculdade deles lá dá filmes, indica filmes pra nós é isso. Também, às vezes a gente sai para fora em biologia, a gente sai pega uma planta vai no laboratório lá a gente olha no aparelho. (Tatiana)

Tomazetti et al (2012) encontraram resultados semelhantes nas manifestações dos sujeitos entrevistados para sua pesquisa. Segundo a autora, os alunos reivindicam metodologias diferenciadas por parte do professor, destacando o desejo de aulas práticas em que os estudantes dizem conseguir compreender, interagir e participar mais das aulas.

As metodologias utilizadas pelos professores podem ser um grande incentivo para a participação dos alunos na sala. Isso pode ser percebido no excerto acima, quando Tatiana revela que na aula de Biologia utiliza o laboratório e quando os professores levam a turma para a sala de informática ou trazem livros da universidade para os alunos. $O$ fato de o professor tirar a turma da sala de aula, em que todos os dias os alunos estão, e utilizar outros espaços da escola demonstra ser motivador para os alunos.

De acordo com as diretrizes curriculares nacionais para o ensino médio é importante que o currículo tenha metodologias de ensino e de avaliação de aprendizagem que mobilizem as ações dos estudantes (Brasil, 2012), porém, apesar de estar contemplado nas diretrizes, na prática nem sempre isso ocorre, às vezes porque os professores não sabem como fazer e, outras vezes, porque o fato de propor metodologias diferenciadas nem sempre é compreendido pelos jovens estudantes como uma forma diferenciada de ensinar, mesmo porque nem os professores se sentem seguros nestas novas formas. Estes são pressionados a todo o momento a adaptarem-se as demandas dos jovens estudantes, mas sem deixar de atender as demandas da escola, que por sua vez são demandas do mercado:

O professor é convidado a adaptar a sua ação ao contexto. A escola e os professores devem elaborar um projeto político-pedagógico levando em conta as características do bairro e dos alunos, mobilizar recursos culturais 
e financeiros que possibilitem melhorar a eficácia e a qualidade da formação, tecer parcerias, desenvolver projetos com os alunos etc. essas novas exigências requerem uma cultura profissional que não é cultura tradicional do universo docente; o professor que não foi e ainda não é formado para tanto, fica um pouco perdido. (Charlot, 2013, p. 100)

Outro fator que explicita a resistência por parte dos alunos diz respeito à comunicação estabelecida entre professor e aluno. Podemos falar, mais precisamente, a respeito da explicação do conteúdo pelo professor na sala de aula. Na abordagem tradicional de ensino, muitas vezes, expressões e conceitos utilizados pelos professores podem não possuir significados para os alunos, dificultando a compreensão (Tomazetti et al, 2012). Freire (1996) assevera que o professor não somente precisa ensinar o conteúdo com clareza, esperando que o educando fixe a matéria dada, mas, sobretudo, necessita fornecer materiais que auxiliem o aluno na compreensão do conteúdo. Os jovens desta pesquisa percebem que não estão aprendendo o conteúdo, seja pela prática de metodologias inadequadas, seja pela ausência da explicação do conteúdo pelo professor:

as aulas tipo, ah eu voltei pro (nome da escola) também porque as aulas lá (escola que o aluno encontrava-se anteriormente) as professoras só chegavam, só passavam um conteúdo só jogavam as coisas e já davam exercício e não explicavam o conteúdo; no (nome da escola) não, tu não precisa copiar porque eles falam, falam, e depois eles passam exercício. (Ozias)

De acordo com Freire (1996, p. 118), "ensinar não é transferir conteúdo a ninguém, assim como aprender não é memorizar o perfil do conteúdo transferido". Para o autor, o ensino está relacionado a um esforço metodicamente crítico de desvelar a compreensão de algo, isto é, apoiar o aluno para que supere sua incompetência provisória e seja protagonista da sua própria aprendizagem. A manifestação de Ozias sugere que também a falta de explicação de um conteúdo pode gerar uma reação do aluno.

Essa forma de atuar na escola se inspira na escola tradicional, mas não realiza o processo para que o aluno aprenda o conteúdo. Uma das características da escola tradicional é a de que o professor "explica o conteúdo da aula e as regras da atividade e o aluno aplica o que lhe foi ensinado". Porém, de acordo com o que foi narrado pelo jovem, essa escola não consegue cumprir as etapas para que o aluno possa realizar a atividade. Essa forma de atuar na escola também não se caracteriza com uma escola construtivista, que rompe com o modelo tradicional e mobiliza o pensamento do aluno para que ele possa construir as respostas que "são vias de acesso ao saber" e a função do professor é "pôr em circulação significações desconhecidas pelo aluno" (Charlot, 2013, p. 112).

Os resultados encontrados nesta pesquisa parecem indicar algo semelhante aos estudos de Tomazetti et al (2012, p. 77) que afirma que os jovens "estão solicitando um papel mais ativo e comprometido do professor para com sua aprendizagem" e reclamam mais atenção para suas dificuldades de aprendizagem. Os jovens indicam que desejam aprender, mas parece existir uma fragilidade na forma de ensinar e escolher o conteúdo, o que podemos caracterizar como ensino ruim.

Para Steiner (2005, p. 31),

o ensino ruim, a rotina pedagógica, um estilo de instrução cínico - quer seja o cinismo consciente ou não - são perniciosos. Destroem a esperança 
pelas raízes. O mau ensino é, quase literalmente, assassino e, metaforicamente, um pecado. Ele diminui o aluno, reduz a uma insanidade abjeta 0 assunto apresentado. Impregna a sensibilidade [...] com o mais corrosivo dos ácidos, o tédio, com os eflúvios perniciosos do enfado.

Além disso, os jovens também percebem que podem reivindicar aquilo que eles gostam que faça sentido para eles. Como podemos ver na sequência, a jovem, quando indagada sobre o que mais gosta da escola, se dá conta de que pode ser ouvida:

Tem aulas de flauta, tudo que é aula para envolver botar os adolescentes no colégio eu venho eu gosto que tem novas ideias. $E$ a escola sempre ouve nossas ideias que a gente pediu bastante que tivesse aulas de outras disciplinas que não tenham no currículo. Eu gosto da escola por isso quando ela tem novidade para gente. (Tatiana)

A escola púbica vivenciou uma abertura de suas portas para as camadas menos favorecidas da sociedade, no entanto, ainda não está consolidada uma reestruturação escolar para essa nova realidade (Dayrell, 2007). Esse processo deve superar a abertura das portas, alcançando pontos de diálogo com os sujeitos e suas realidades. A postura de escuta tanto do jovem para a escola como da escola para com o jovem é um fator muito importante para a construção de uma relação menos conflituosa, mais harmônica e respeitosa entre escola e alunos.

Para isso, segundo Freire (1996), é necessário uma disponibilidade para o diálogo, isto é, uma experiência de abertura ao outro (o aluno), a seu contexto e às condições de seu contorno ecológico, social e econômico. A disponibilidade é a experiência de encurtar a distância geográfica e social existente entre o professor e o aluno. Nas palavras do autor, "testemunhar a abertura aos outros, a disponibilidade curiosa à vida, a seus desafios, são saberes necessários à prática educativa. Viver a abertura respeitosa aos outros [...] deveria fazer parte da aventura docente" (Freire, 1996, p. 135).

\section{Considerações finais}

O objetivo inicial desse trabalho foi o de compreender os motivos que levam os jovens a se afastarem dos processos formativos escolares. Para isso, buscou-se compreender os modos de vida dos jovens, as dimensões do tempo construídas por eles e entender suas relações com os professores e colegas, utilizando os fundamentos da pesquisa etnográfica.

Verificamos que a infrequência inicia-se ainda no ensino fundamental, evidenciando uma fragilidade do vínculo entre a escola e o aluno. Gera-se, com isso, um processo de resistência, representativo desse vínculo frágil.

Dessa forma, foi possível refletir sobre caminhos possíveis para o fortalecimento do laço escola-aluno. O uso de metodologias mais condizentes com o tempo de vida dos alunos e até mesmo a utilização de outros espaços da escola que não somente a sala de aula mostram-se como alternativas para a motivação, participação e permanência dos alunos na escola. Da mesma forma, parece ser apropriada uma postura de escuta, uma disponibilidade para o diálogo, uma experiência de abertura ao aluno e ao contexto em que se encontra com o fim de aproximar escola e jovem. 
Essa pesquisa nos desafia a pensar nas políticas públicas no momento em que só poderemos qualificar as políticas voltadas à juventude se dermos voz a esses jovens em uma disponibilidade ao diálogo.

\section{Referências}

ABRANTES, Pedro. Os sentidos da escola: identidades juvenis e dinâmicas de escolaridades. Oeiras: Celta, 2003.

ANDRE, Marli; LÜDKE, Menga. Pesquisa em educação: abordagens qualitativas. São Paulo: EPU, 2000.

BRASIL. Constituição da República Federativa do Brasil. Brasília: Senado Federal, 1988.

BRASIL. Lei de diretrizes e bases da educação nacional: n. 9394/96. Brasília: Senado Federal, 1996.

BRASIL. Resolução n. 2 de 30 de janeiro de 2012. Diretrizes curriculares nacionais para o ensino médio. Brasília: MEC, 2012.

CHARLOT, Bernard. Da relação com o saber às práticas educativas. São Paulo: Cortez, 2013.

DAYRELL, Juarez. O jovem como sujeito social. Revista Brasileira de Educação. Anped, n. 24, 2013, p. 40-52.

DAYRELL, Juarez. A escola faz as juventudes? Reflexões em torno da socialização da juventude. Educação e Sociedade. Campinas, v. 28, n. 100, 2007, p. 1105-1128.

DELEUZE, Giles; GUATTARI, Félix. O liso e o estriado. In: DELEUZE, Giles; GUATTARI, Félix. Mil platôs: capitalismo e esquizofrenia. Rio de Janeiro: 34, 1997.

FREIRE, Paulo. Pedagogia da autonomia: saberes necessários à prática educativa. São Paulo: Paz e Terra, 1996.

LÜDKE, Menga; ANDRÉ, Marli. Pesquisa em educação: abordagens qualitativas. São Paulo: EPU, 1986.

MOEHLECKE, Sabrina. O ensino médio e as novas diretrizes curriculares nacionais: entre recorrências e novas inquietações. Revista Brasileira de Educação. Rio de Janeiro, v. 17, n. 49, 2012, p. 39-58.

ORTÍ, Alfonso. La apertura y el enfoque cualitativo o estrutural. In: FERNANDO, Manuel Garcia. El análisis de la realidad social métodos y técnicas de investigación. Madrid: Alianza, 1989, p. 171-203.

PAIS, José Machado. Buscas de si: expressividades e identidades juvenis. In: ALMEIDA, Maria Isabel Mendes; EUGENIO, Fernanda (orgs.). Culturas jovens: novos mapas do afeto. Rio de Janeiro: Jorge Zahar, 2006, p. 7-21.

RIO GRANDE DO SUL. Proposta pedagógica par o ensino médio politécnico e educacional profissional integrada ao ensino médio. Porto Alegre: SEC, 2011.

SILVERMAN, David. Interpretação de dados qualitativos: métodos para análise de entrevistas, textos e interações. Porto Alegre: Artmed, 2009.

SPOSITO, Marilia Pontes. Algumas reflexões e muitas indagações sobre as relações entre escola no Brasil. In: ABRAMO, Helena: BRANCO, Pedro Paulo Martoni (orgs.). Retratos da juventude brasileira: análises de uma pesquisa nacional. São Paulo: Instituto Cidadania; Funções Perseu Abramo, 2005, p. 87-128.

STEINER, George. Lições dos mestres. Rio de Janeiro: Record, 2005. 
TOMAZETTI, Elisete et. al. Os sentidos do ensino médio: olhares juvenis sobre a escola contemporânea. São Leopoldo: Oikos, 2012.

Ethiana Sarachin da Silva Ramos é mestranda no Programa de Pós-Graduação em Educação da Universidade Federal de Santa Maria.

Endereço: Rua dr. Leovegildo Leal de Moraes, 350 - 97110-820 - Santa Maria - RS Brasil.

E-mail: ethianasarachin@hotmail.com.

Sueli Salva é professora no Departamento de Metodologia do Ensino e no Programa de Pós-Graduação em Educação da Universidade Federal de Santa Maria, doutora em Educação pela Universidade Federal do Rio Grande do Sul. Endereço: Avenida Roraima, 1000 - 97105-900 - Santa Maria - RS - Brasil. E-mail: susalvaa@gmail.com.

Recebido em 15 de abril de 2014.

Aceito em 3 de junho de 2014. 